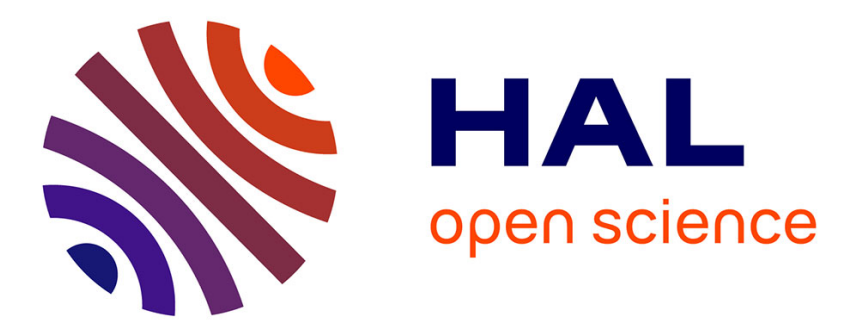

\title{
The effect of dynamic recrystallization on olivine crystal preferred orientations in mantle xenoliths deformed under varied stress conditions
}

Gyorgy Falus, Andrea Tommasi, Vincent Soustelle

\section{- To cite this version:}

Gyorgy Falus, Andrea Tommasi, Vincent Soustelle. The effect of dynamic recrystallization on olivine crystal preferred orientations in mantle xenoliths deformed under varied stress conditions. Journal of Structural Geology, 2011, 33 (11), pp.1528-1540. 10.1016/j.jsg.2011.09.010 . hal-00669963

\section{HAL Id: hal-00669963 https://hal.science/hal-00669963}

Submitted on 22 Feb 2022

HAL is a multi-disciplinary open access archive for the deposit and dissemination of scientific research documents, whether they are published or not. The documents may come from teaching and research institutions in France or abroad, or from public or private research centers.
L'archive ouverte pluridisciplinaire HAL, est destinée au dépôt et à la diffusion de documents scientifiques de niveau recherche, publiés ou non, émanant des établissements d'enseignement et de recherche français ou étrangers, des laboratoires publics ou privés.

\section{(ㄷ)(1) $\$$}

Distributed under a Creative Commons Attribution - NonCommercial| 4.0 International 


\title{
The effect of dynamic recrystallization on olivine crystal preferred orientations in mantle xenoliths deformed under varied stress conditions
}

\author{
Gyorgy Falus ${ }^{\mathrm{a}, \mathrm{b}, *}$, Andréa Tommasi $^{\mathrm{b}}$, Vincent Soustelle ${ }^{\mathrm{b}}$ \\ ${ }^{a}$ Eötvös Loránd Geophysical Institute of Hungary, 1145 Budapest, Hungary \\ ${ }^{\mathrm{b}}$ Géosciences Montpellier, CNRS and Université Montpellier 2, 34095 Montpellier, France
}

\begin{abstract}
Spinel peridotite xenoliths from Persani Mountains, Southeastern Carpathians, Romania, were submitted to deformation by dislocation creep accompanied by dynamic recrystallization under variable stress and temperature conditions. Predominance of low-angle boundaries parallel to (100) with welldefined $[0 \mathrm{vw}]$ rotation axes in olivine indicates that subgrain rotation is the main recrystallization mechanism and that dislocation glide occurs mainly in $[100]\{0 \mathrm{kl}\}$ systems. Analysis of olivine crystal preferred orientations highlights that recrystallization results in dispersion of the orientations of recrystallized grains relatively to the parent grains. This dispersion may be quantified by a dimensionless dispersion factor defined as the ratio of the random component of the [100] axis distributions between the recrystallized grains and porphyroclasts. This factor is largely independent from the overall fabric strength, the number of grains analyzed, and the recrystallized grain size. The olivine CPO strength and anisotropy at the rock scale, quantified by J-index, are largely controlled by the volume of recrystallized grains, which depends on finite strain. Comparison of olivine CPO in coarse- and finegrained porphyroclastic peridotites shows that deviatoric stress and temperature conditions play nevertheless a role on the CPO evolution during recrystallization; selective grain growth, which is favored at high temperature and low stresses, does counteract the dispersion produced by the nucleation processes.
\end{abstract}

\section{Introduction}

Crystal preferred orientation (CPO) of olivine in the upper mantle results in anisotropy of many physical properties, such as seismic velocities, thermal diffusivity, electric conductivity, and plastic deformation (e.g., Kobayashi, 1974; Nicolas and Christensen, 1987; Mainprice et al., 2000; Tommasi and Vauchez, 2001; Tommasi et al., 2001, 2009; Gatzemeier and Tommasi, 2006). The evolution of olivine CPO in upper mantle rocks is essentially controlled by plastic deformation through crystal reorientation during intracrystalline deformation by dislocation glide (Nicolas et al., 1973; Takeshita et al., 1990; Wenk et al., 1989; Tommasi et al., 2000). It may, however, be modified by recrystallization processes: nucleation, subgrain rotation, and

\footnotetext{
* Corresponding author. Eötvös Loránd Geophysical Institute of Hungary, 1145 Budapest, Hungary.

E-mail address: falus@elgi.hu (G. Falus).
}

grain boundary migration (GBM). These processes may either strengthen or weaken the CPO (e.g., Carter, 1976; Tommasi et al., 2000) or even, as it has been observed in simple shear experiments, modify the symmetry of the CPO relative to the imposed deformation, leading to parallelism between the dominant slip system and the macroscopic shear (Karato, 1988; Zhang and Karato, 1995; Bystricky et al., 2000). Experimental data for periclase at very high shear strains suggest that recrystallization may even result in a complete change in the CPO (Heidelbach et al., 2003). The final CPO depends on which process predominates, which in turn depends on several factors, such as temperature, deviatoric stress, strain rate, deformation regime, presence of fluids/melts, etc.

Laboratory experiments, although largely contributing to the understanding of the interactions between different processes during deformation and recrystallization, are orders of magnitude away in strain rate and stress from the conditions of natural deformation processes. Dynamic recrystallization is a time (or strain rate) dependent process, since it is controlled by the interplay between dislocation glide, which results in enhancement in 
the grains' internal energy due to accumulation of dislocations, and diffusive processes that allow reorganization and reduction of the dislocation population in a crystal. To investigate the effect of dynamic recrystallization on the microstructure and olivine CPO under geological strain rates, we performed detailed microstructural observations and CPO measurements in a series of mantle xenoliths from the Southeastern Carpathians. These xenoliths are spinel peridotites that record deformation by dislocation creep under a range of temperature, stress and strain rate conditions, which resulted in a wide variety of microstructures. Two-pyroxenes thermometry indicates that they equilibrated at temperatures ranging between $1020^{\circ} \mathrm{C}$ for the coarser-grained ones and $850^{\circ} \mathrm{C}$ for the finest-grained mylonites; conversion of these equilibrium temperatures into depths based on the local geotherm implies that these xenoliths sample a $35-55 \mathrm{~km}$ depth section of the lithospheric mantle in a convergent continental margin (Falus et al., 2008).

\section{Microstructures}

Several hundreds of mantle xenoliths have been collected from basalt eruption localities of the Persani Mountains in the southern Carpathians (Fig. 1). These xenoliths are mostly coarse-grained spinel peridotites, but mylonitic and ultramylonitic textures are observed in $\sim 15 \%$ of the sampled xenoliths. Twenty-seven xenoliths representative of the entire textural range have been selected for study. Microstructures were characterized by optical analysis of polished thin sections perpendicular to the foliation and subparallel to the lineation (XZ sections). In a few coarse-grained samples, the foliation and lineation could not be determined macroscopically and thin sections were cut in a random orientation.
The studied mantle xenoliths present a continuous gradation from coarse-grained porphyroclastic to fine-grained mylonitic textures (Fig. 2). Coarse porphyroclastic xenoliths are characterized by olivine and pyroxene porphyroclasts ranging from 500 to $3000 \mu \mathrm{m}$ in diameter and displaying sutured grain boundaries. These porphyroclasts are generally weakly elongated with aspect ratios of $1: 2$. This elongation marks the lineation in these xenoliths, whereas a weak compositional layering and moderately flattened grain shapes indicate the foliation. Olivine porphyroclasts exhibit well-developed and widely spaced subgrain boundaries, dominantly parallel to the (100) crystallographic plane (Fig. 2). Recrystallized olivine grains, when they can be clearly identified, are relatively coarse $(300-500 \mu \mathrm{m})$ and more equidimensional. However, the most coarse-grained samples show a continuous variation in grain size that hinders the distinction between porphyroclasts and recrystallized grains. Orthopyroxene porphyroclasts have irregular shapes, not showing any clear elongation. Small interstitial orthopyroxene forming dispersed aggregates aligned in the foliation are observed in some samples, contributing to the compositional layering. Clinopyroxenes are generally finer grained (500$1000 \mu \mathrm{m})$ and often display interstitial shapes.

Mylonitic peridotites are characterized by an increase in the volume of recrystallized grains and a decrease in recrystallized grain size, which ranges from 80 to $300 \mu \mathrm{m}$ in the coarser mylonites to $40-60 \mu \mathrm{m}$ in the most recrystallized peridotites (Fig. 2). The grain size of olivine porphyroclasts does not vary significantly relatively to the coarse-grained peridotites. However, the porphyroclasts are more elongated (aspect ratios in the $X Z$ plane range from $1: 3$ to $1: 10$ ). This gives rise to a more intense lineation and foliation in these xenoliths. Their
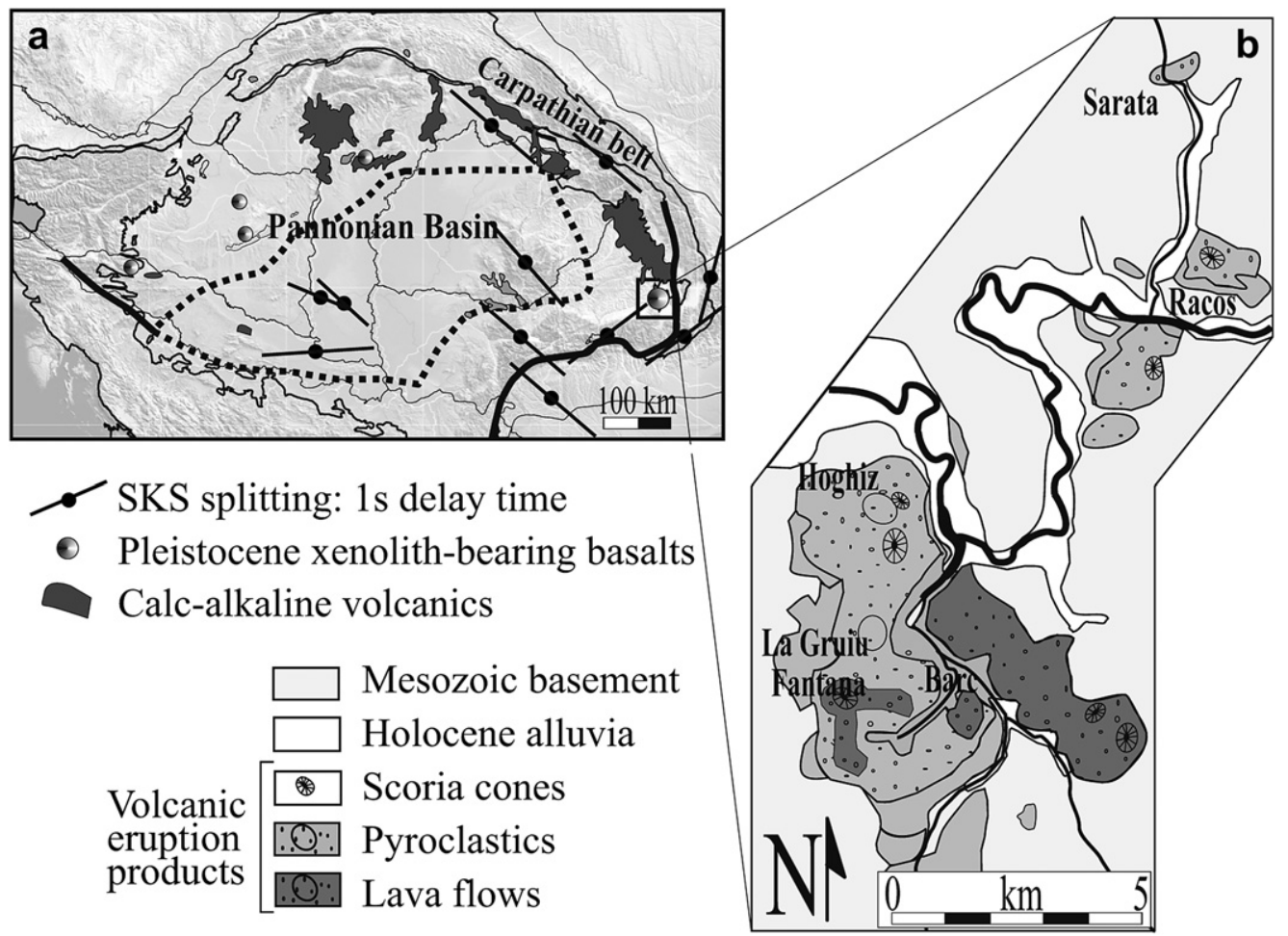

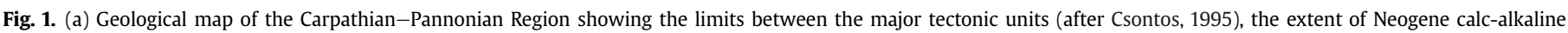

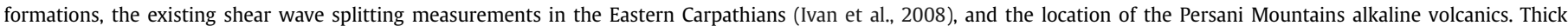

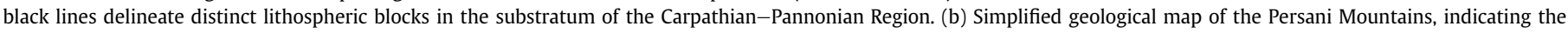
different eruption products (after Panaiotu et al., 2004). Mantle xenoliths have essentially been collected in Trestia Valley (NV) and Barc (BC, BGT). 

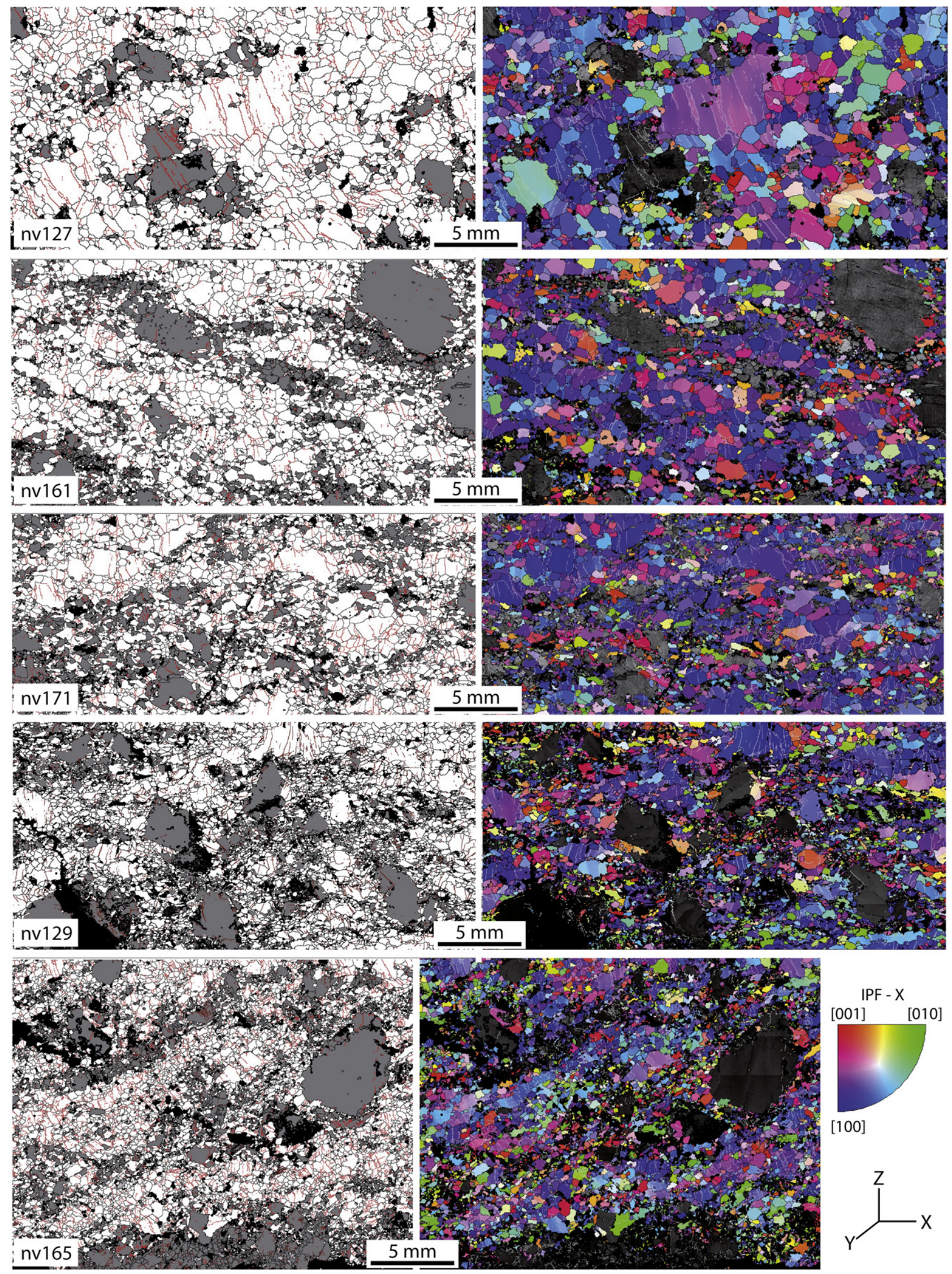

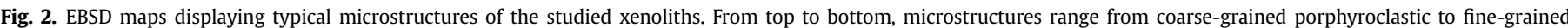

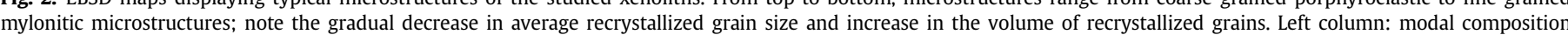


internal deformation is strong with undulose extinction and finely paced subgrain boundaries, sometimes forming a mosaic substructure. Recrystallized grains often display evidence for internal strain and are elongated subparallel to the lineation defined by the porphyroclasts' elongation. Grain boundaries of both olivine porphyroclasts and recrystallized grains are usually sutured, except for the finest grains in the mylonites, which tend to be more polygonal with gently curved boundaries. Enstatite porphyroclasts are rich in exsolution lamellae and often kinked. They may be either extremely elongated or irregularly shaped with abundant concave embayments; the latter show no shape preferred orientation. Fine-grained intergranular orthopyroxene and clinopyroxene also occur as small crystals dispersed in the recrystallized matrix; these crystals usually have irregular, interstitial-like shapes and form dispersed aggregates forming an anastomosing banding subparallel to the foliation. These finegrained pyroxene aggregates are not directly associated with the porphyroclasts. Orthopyroxene porphyroclasts, even the most elongated ones, do not show fine-grained recrystallization tails.

Recrystallized grain sizes in the studied mantle peridotites were estimated using grain size data acquired through EBSD mapping (Fig. 2). Use of the inflection point of the grain size frequency curves enabled distinction of recrystallized grains from porphyroclasts, even in the coarse-grained xenoliths, which show a more continuous grain size distribution. Average recrystallized grain size of the peridotites varies continuously from $40 \mu \mathrm{m}$ in the finest-grained mylonites to $500 \mu \mathrm{m}$ in the coarser-grained porphyroclastic peridotites. Paleostress values estimated using these average recrystallized grain sizes range from 7 to $12 \mathrm{MPa}$ in the coarse-grained samples to $62-75 \mathrm{MPa}$ in the fine-grained mylonites; lower values are estimated using the piezometer of Van der Wal et al. (1993) whereas higher ones are derived applying the piezometer of Karato et al. (1980). Recrystallized grain sizes are directly correlated with equilibrium temperature (Falus et al., 2008). Although the finer grain sizes in the mylonites may allow for lower closure temperatures of the diffusion systems on which the thermometers are based; this correlation is consistent with deformation of the mylonites at lower temperatures and higher deviatoric stresses and/or strain rates (Austin and Evans, 2007).

\section{Olivine crystal preferred orientations}

Olivine and pyroxene crystal preferred orientations (CPO) were determined at Geosciences Montpellier using a JEOL 5600 scanning electron microscope equipped with an EBSD system from Oxford HKL Technology. Accelerating voltage of $17 \mathrm{kV}$ and $25 \mathrm{~mm}$ working distance were used. The sample stage was tilted to $70^{\circ}$. Data were acquired and treated using the Channel 5 software package. Automatic orientation mapping was carried out in $\mathrm{a} \approx 10 \times 20 \mathrm{~mm}$ area of the studied xenoliths (large areas were mapped in the coarse-grained peridotites). Depending on grain size, a step size between 10 and $100 \mu \mathrm{m}$ was used (the step size was set to be always 4-5 times smaller than the average recrystallized grain size)

In all studied xenoliths, olivine displays clear crystallographic preferred orientations (Fig. 3), which indicate that dislocation creep was the principal deformation mechanism. Olivine [100] axes form a single maximum aligned with the lineation defined by the elongation of the porphyroclasts. The [010] axes form a girdle normal to the lineation with a maximum normal to the foliation and [001] axes tend to be perpendicular to the lineation in the foliation plane or to form a girdle at high angle to the lineation. The orientation distribution of the olivine crystal axes is characteristic of deformation by slip on $[100]\{0 \mathrm{kl}\}$ systems with dominant activation of (010) planes. This interpretation, which was already proposed in early studies of olivine fabrics (e.g., Avé Lallemant and Carter, 1970), is confirmed by numerical simulations of CPO evolution in olivine polycrystals that allow direct correlation of slip systems activity to the CPO (e.g., Wenk et al., 1989; Takeshita et al., 1990; Tommasi et al., 2000).

Analysis of the olivine CPO variation in the entire xenolith collection shows that coarse-grained peridotites tend to show stronger CPO than the mylonites (Fig. 3). Comparison between CPO of olivine porphyroclasts and recrystallized grains within a sample highlights that the orientations are similar: maximum and minimum concentrations clearly coincide, but the recrystallized grains CPO has a higher dispersion. This suggests that recrystallization leads to a decrease in CPO strength.

A standard parameter for measuring the strength of CPO is the Jindex. It represents the volume-averaged integral of the squared orientation densities, which is sensitive to peaks in the orientation distribution function (Bunge, 1982). For a random distribution $J=1$ and for a single crystal (perfect CPO) $J$ is infinite. Natural samples of mantle peridotites display olivine $J$-index $\left(\mathrm{JOl}_{\mathrm{Ol}}\right)$ in the range $2-25$, with a peak at $8-10$, and only a few have $J_{\mathrm{Ol}}>20$ (Ben Ismail and Mainprice, 1998; Tommasi et al., 2000). The J-index of olivine CPO in the studied xenoliths has been calculated using the program SuperJ7x by D. Mainprice (ftp://www.gm.univ-montp2.fr/mainp rice//CareWare_Unicef_Programs/) with a $10^{\circ}$ Gaussian halfwidth, data at $1^{\circ}$ bins, and truncation of the orientation distribution function (ODF) at degree 22. It ranges between 3.5 and 11, if it is calculated using one measurement per pixel of the EBSD map. Lower values, between 1.8 and 7, are obtained using one average orientation per grain (Fig. 4a). This difference results from the large area occupied by the coarse porphyroclasts that have stronger CPO (Fig. 3). The lowest bulk $J$-indexes are observed in the xenoliths with finest recrystallized grain sizes and the highest $J$-indexes correspond to the coarse porphyroclastic peridotites, suggesting a relation between recrystallized grain size and fabric strength (Fig. 4a).

To quantitatively compare the strength of olivine CPO of the porphyroclasts and recrystallized grains, the J-index of the two populations was also estimated (Fig. 4b). One should note that even if the number of porphyroclasts in a given sample is always significantly lower than the recrystallized grains one, in most samples more than 100 porphyroclasts were measured, ensuring a correct estimation of the $J$-index porph. Indeed the $J$-index decreases asymptotically with the number of the grains considered in the calculation, but the variation is negligible for more than 100 crystal orientations (Ben Ismail and Mainprice, 1998).

\section{Misorientation data}

The activation of specific slip systems is expected to produce not only distinct crystallographic preferred orientations, but also

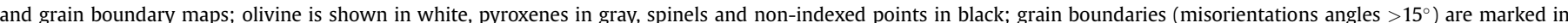

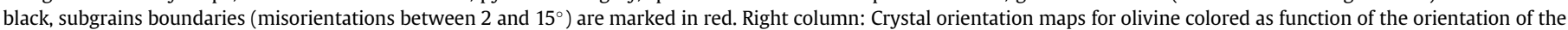

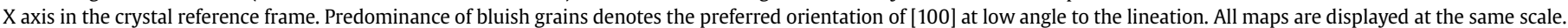


grain misorientation relations within and between adjacent grains, since the rotation across low-angle grain boundaries is directly related to the dislocations that form the boundary (Amelinckx and Dekeyser, 1959). The rotation axes that accommodate these misorientations give therefore an indication of the slip systems active during deformation (Poirier and Nicolas, 1975; Darot and Gueguen, 1981; Fliervoet and White, 1995; Lloyd et al., 1997).

Strong predominance of low angles $\left(<10^{\circ}\right)$ in the correlated misorientation distribution, that is the variation in orientation between neighboring pixels, suggests that dynamic recrystallization is controlled by subgrain rotation in all samples (Fig. 5). Rotation axes accommodating intracrystalline misorientations, both diffuse or at low-angle grain or subgrain boundaries $\left(<15^{\circ}\right)$, are quite uniform throughout the whole xenolith suite studied (Fig. 3); they are systematically close to [OVW] orientations, with clear maxima around [001] and [010]. This, together with the observation that the trace of the subgrain boundary planes is systematically normal to [100], implies that subgrain walls are mostly formed by dislocations of [100] $\{0 \mathrm{kl}\}$ slip systems. "Pencil glide", i.e., activation of various slip systems sharing a common Burgers vector, results indeed in formation of low-angle tilt boundaries normal to the Burgers vector (Amelinckx and Dekeyser, 1959). The misorientation across the boundary is controlled by the relative density of the dislocations of each system. In olivine, for instance, predominance of $[100](010)$ or [100](001) edge dislocation results in [001] or [010] rotation axes, respectively. In the studied peridotites, we observe either similar densities for [010] and [001] rotation axes or a predominance of [010] (Fig. 3), suggesting that slip on (001) planes dominates. This observation is nevertheless in contrast with the CPO data, which shows a preferential orientation of [010] normal to the foliation and of [001] in the foliation plane normal to the lineation, implying preferential activation of the (010)[100] slip system. This partial inconsistency between olivine СPO and misorientation data has also been observed in other peridotite suites (Tommasi et al., 1999; Soustelle et al., 2010). It suggests that dislocations frozen in subgrain boundaries may not be fully representative of the slip systems activity. Finally, in the mylonites, rare subgrain boundaries with a trace normal to [001] are also observed, forming a polygonal subgrain structure and marking the activation of [001] slip systems. This is accompanied by the observation of low-angle rotations with more varied orientations, although orientations close to [0VW] still dominate.

\section{Discussion}

The similarities in crystal preferred orientation patterns between recrystallized and porphyroclastic grains (Fig. 3) imply that the recrystallization process is crystallographically-controlled. This, together with the high proportion of low-angle grain boundaries and their consistent rotation axes (Figs. 3 and 5), suggests that subgrain rotation is the dominant nucleation process, but we cannot exclude a contribution of grain boundary migration to nucleation (bulging). The latter process probably plays a more important role in the mylonites as suggested by the more dispersed low-angle rotation axes (Fig. 3 ) and by the stronger variations in orientation between porphyroclasts and neighboring crystals (Fig. 2). In addition, the more homogeneous grain size distribution, the less elongated shapes of the porphyroclasts, and the highly sutured shapes of the grain boundaries in the coarse porphyroclastic peridotites (Fig. 2) suggest that in these samples, which were probably deformed at higher temperature and lower deviatoric stresses, subgrain rotation recrystallization is accompanied by effective grain boundary migration, allowing for selective growth of crystals with low stored energy.

To further characterize the effect of recrystallization on the olivine CPO, we analyzed the variation of the [100], [010], and [001] axes distribution symmetry between porphyroclasts and recrystallized grain populations in each sample using the point $(P)$, girdle $(G)$ and random $(R)$ fabric type indexes (Vollmer, 1990). These indexes are calculated from the eigenvalues $(\lambda 1, \lambda 2, \lambda 3)$ of the normalized orientation matrix (Woodcock and Naylor, 1983; Humbert et al., 1996) for each principal crystallographic axis: $P=\lambda 1-\lambda 3, \quad G=2(\lambda 2-\lambda 3)$, and $R=3 \times \lambda 3$, respectively. The results, presented in Fig. 6a, show a clear shift from medium to high $P$ values (indicating point distributions) for the porphyroclasts toward medium/high $R$ values (random distribution of crystal axes) for the recrystallized grains for both [100] and [010] axes. This shift is most obvious for [100] as illustrated by the relation between the distribution symmetry of porphyroclasts and recrystallized grains in each sample (Fig. 6b). The stronger variation in orientation of the [100] axes relatively to [010] and [001] results directly from the dominant activation of $[100]\{0 \mathrm{kl}\}$ slip systems during deformation. Dislocation glide on these systems results in a stronger concentration of [100] relative to the other crystal axes (Tommasi et al., 2000). On the other hand, organization of $[100]\{0 \mathrm{kl}\}$ dislocations in low-angle boundaries results in dispersion of the CPO by rotation along [0VW] axes, mainly [010] and [001], as observed in the present study (Fig. 3). Thus [100] is expected to be more sensitive to the subgrain rotation recrystallization processes than [010] or [001]. Shift of [100] axis toward higher $G$ values, is observed only in sample NV128. This change from a point to a girdle distribution is consistent with a single rotation axis, which indicates activation of single slip. However, this conclusion is not fully consistent with the misorientation data for this sample that shows that low-angle boundaries with [010] and [001] rotation axes are almost equally common (Fig. 3).

Comparison between the randomness of [100] axes for porphyroclasts and recrystallized shows, however, a weak positive correlation between $R_{\mathrm{r}}$ and $R_{\mathrm{p}}$ (Fig. 7). The strength of recrystallized grains orientation depends therefore on the porphyroclasts' one (the original CPO). This further demonstrates the crystallographic control on nucleation, i.e., orientations of the recrystallized grains are derived from the porphyroclasts, corroborating the major contribution of subgrain rotation to recrystallization. Closer analysis of the orientation maps (Fig. 2) shows, however, that the mylonites are characterized by stronger variations in orientation between porphyroclasts and neighboring grains, suggesting that subgrain rotation is not the sole nucleation process in theses samples.

Since the strongest effect of recrystallization is a change in symmetry of the [100]-axes distribution between porphyroclasts and recrystallized grains populations (Fig. 6), we propose that the dispersion of [100] axes, calculated as $D=R_{\mathrm{r}} / R_{\mathrm{p}}$, that is, the ratio between the random component of the [100] axis distribution of recrystallized grains and porphyroclasts (calculated using the same number of measurements taken in a random order from the total orientation distribution to ensure a weak dependence of the number of grains analyzed), may be used to quantify the "randomization" (dispersion) of crystal axes during recrystallization.

Dispersion values for [100] axes are comprised between 1 and 2.1. The highest value probably represents the maximum dispersion that can be developed through subgrain rotation recrystallization. However, there is neither a relation between recrystallized grain size and the dispersion of [100] nor between the $J$-index of the sample and the dispersion of [100] 
[100]

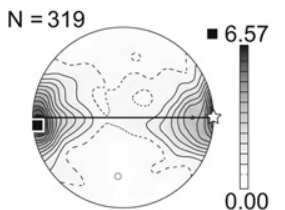

[010]

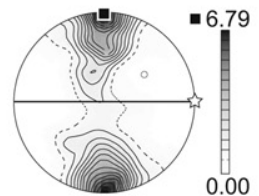

[001]

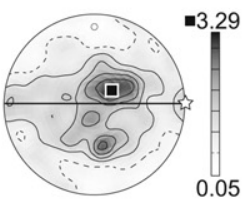

$\mathrm{nv126}-J=6.53$

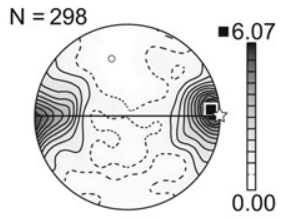

nv122 $-J=6.43$
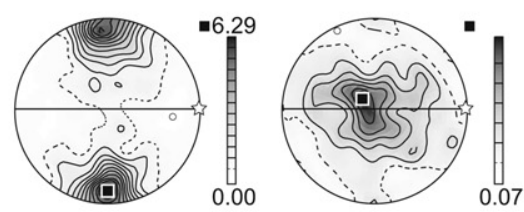

0.07
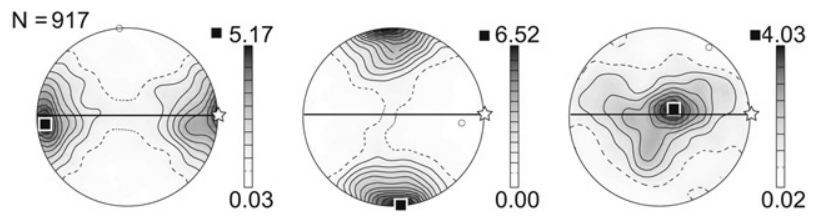

$n v 163-J=5.81$
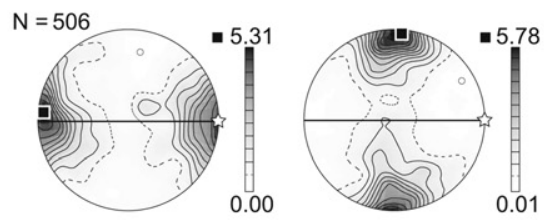

bgt19 $-J=5.63$
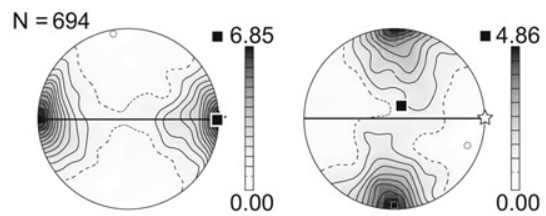

$n v 160-J=5.26$
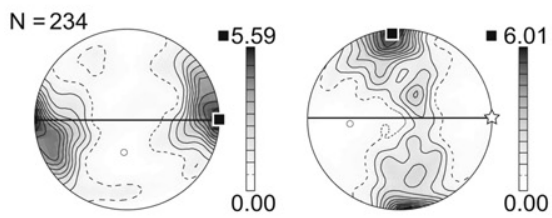

bgt21 $-J=5.25$
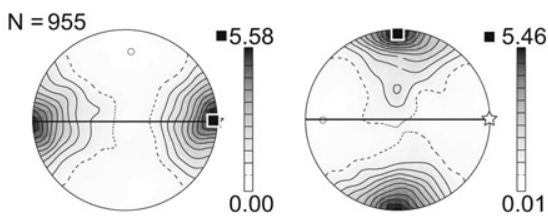

nv127 $-J=5.01$

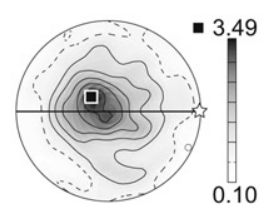

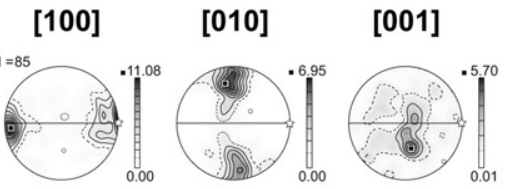
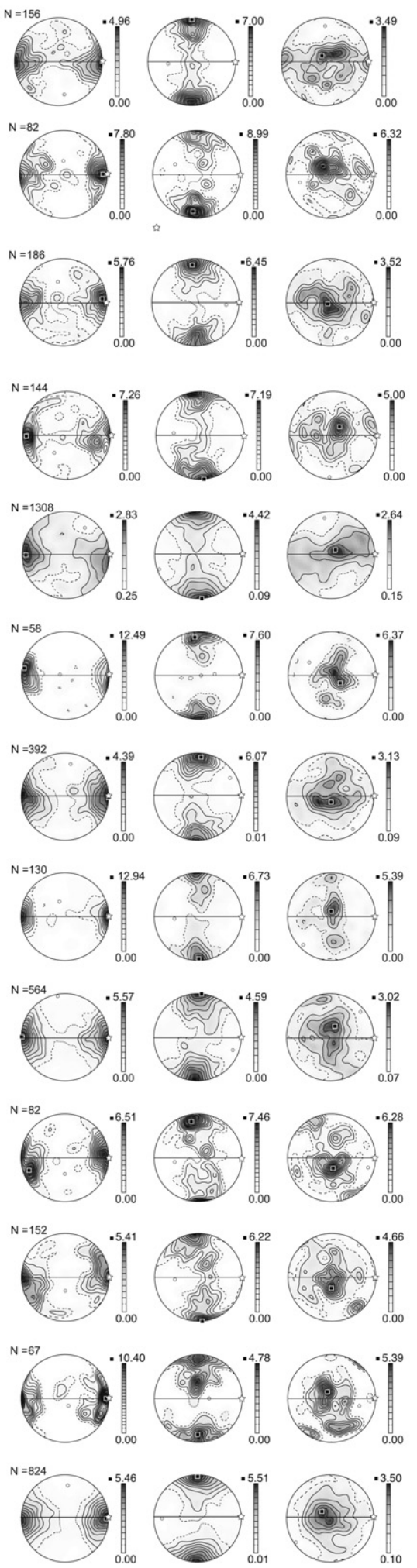

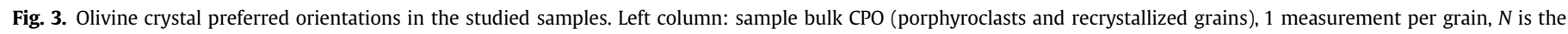

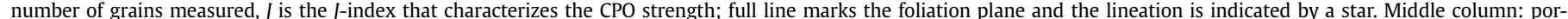

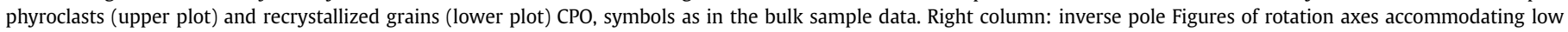
angle $\left(2-15^{\circ}\right)$ misorientations. Lower hemisphere equal area projections, contours at 0.5 multiples of a uniform distribution intervals for all plots. 


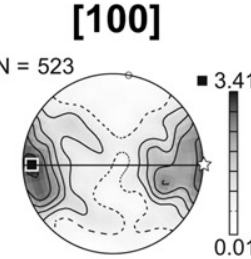

nv121 - $J=4.31$

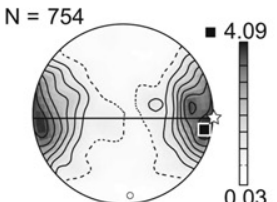

rk123 - J = 4.24

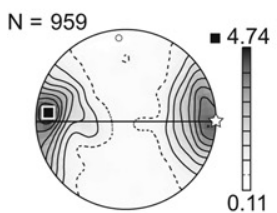

bc122 - J = 4.22

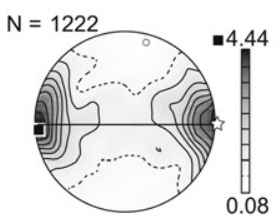

nv164 - J = 3.95

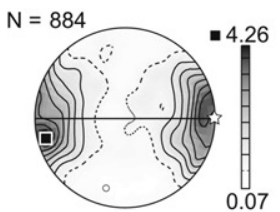

bc121 - $J=3.54$

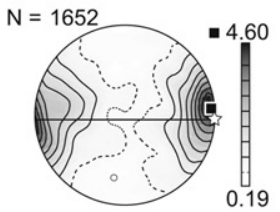

nv169 - J = 3.39

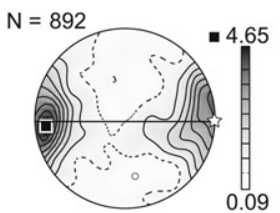

nv166 - J = 3.37
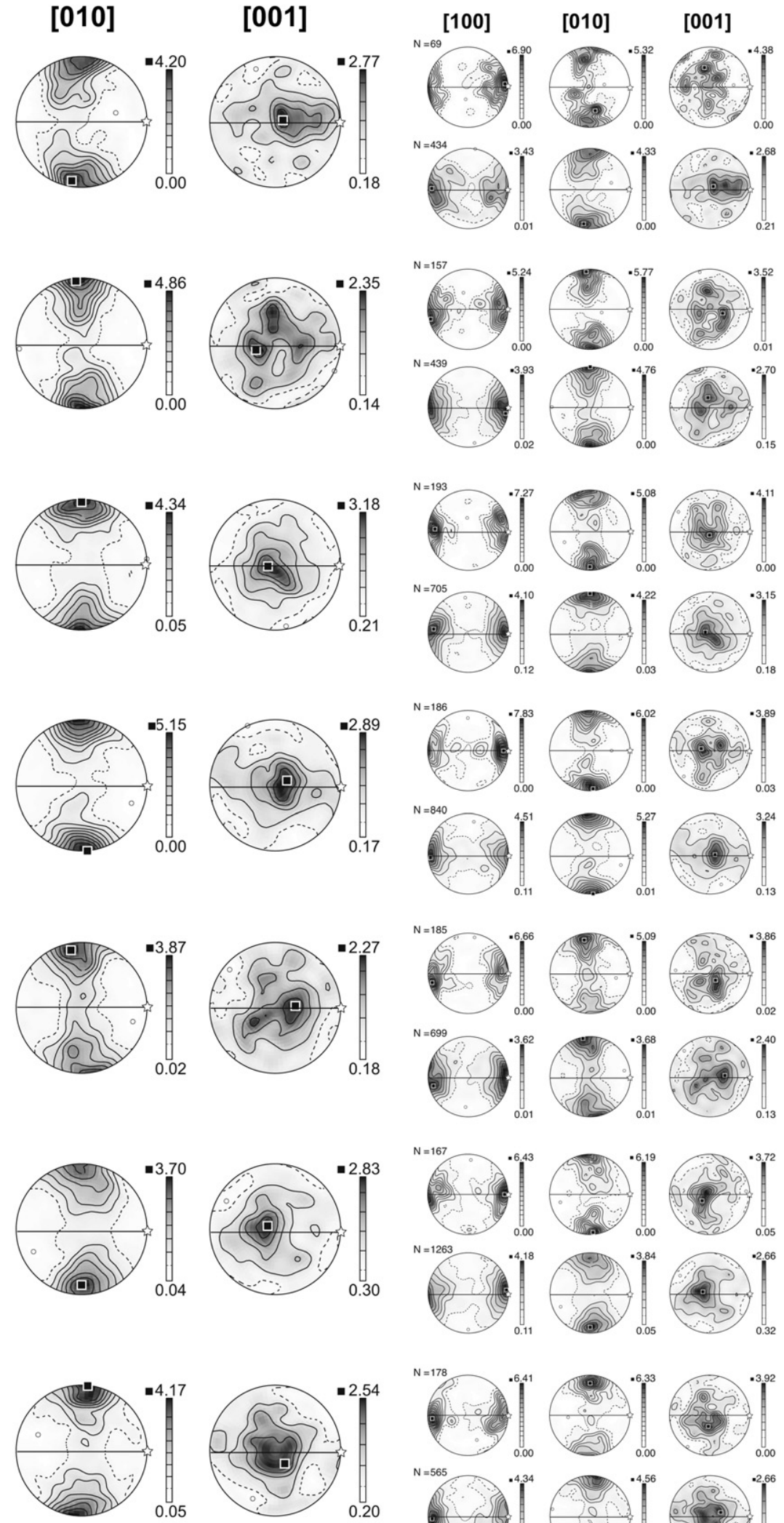
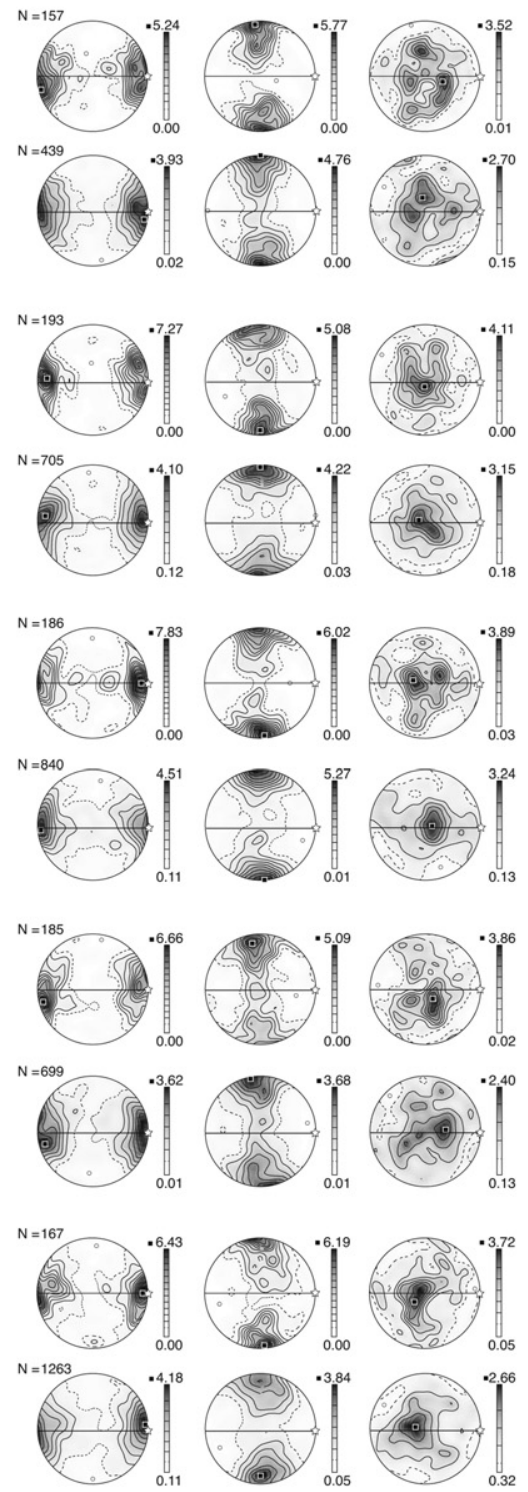
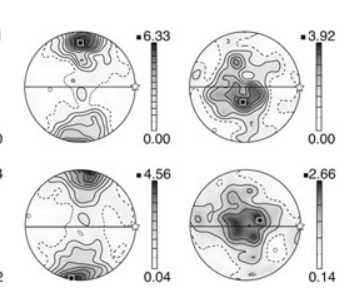
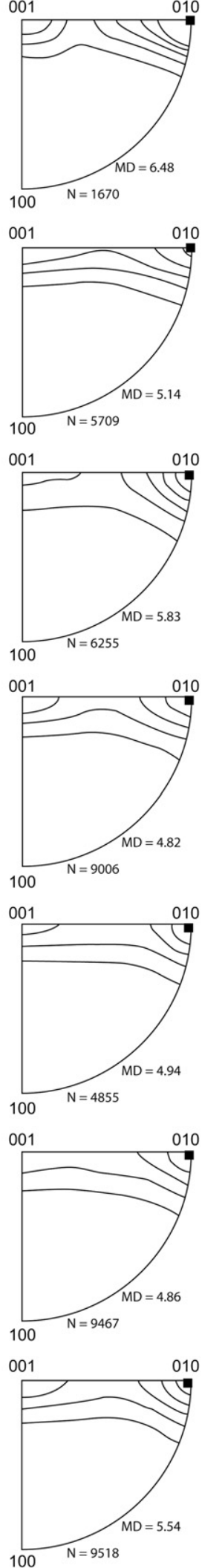

Fig. 3. (continued). 
[100]

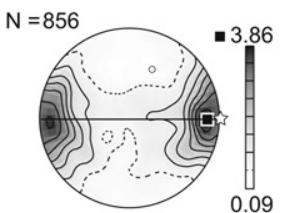

nv125 - $J=3.24$

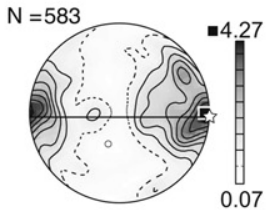

rk122 $-J=3.20$

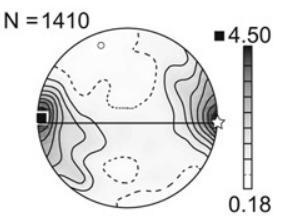

bc101 $-J=3.16$

$\mathrm{N}=2082$

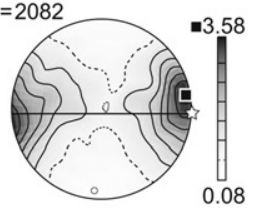

nv128 - J = 3.06

$\mathrm{N}=1858$

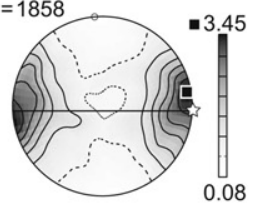

nv171 - $J=2.94$

$\mathrm{N}=1188$

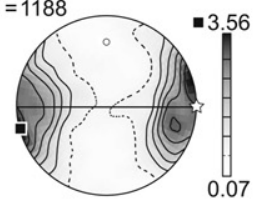

bc123 $-J=2.86$

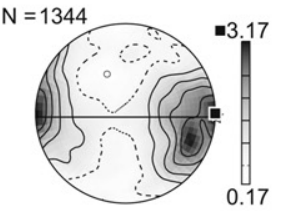

nv123 $-J=2.83$
[010]
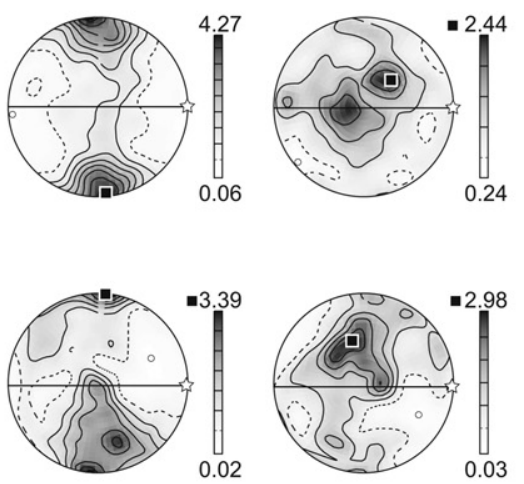

0.03
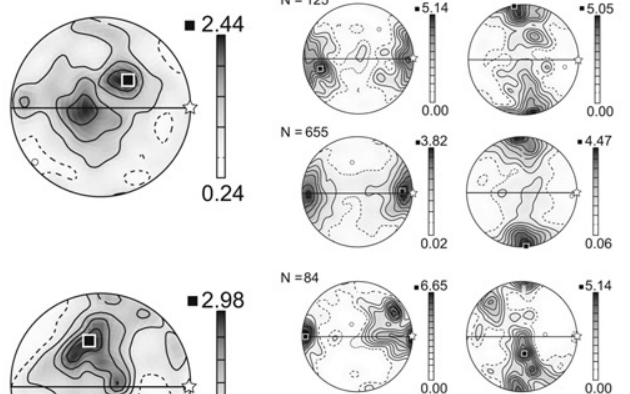

$\mathrm{N}=453$
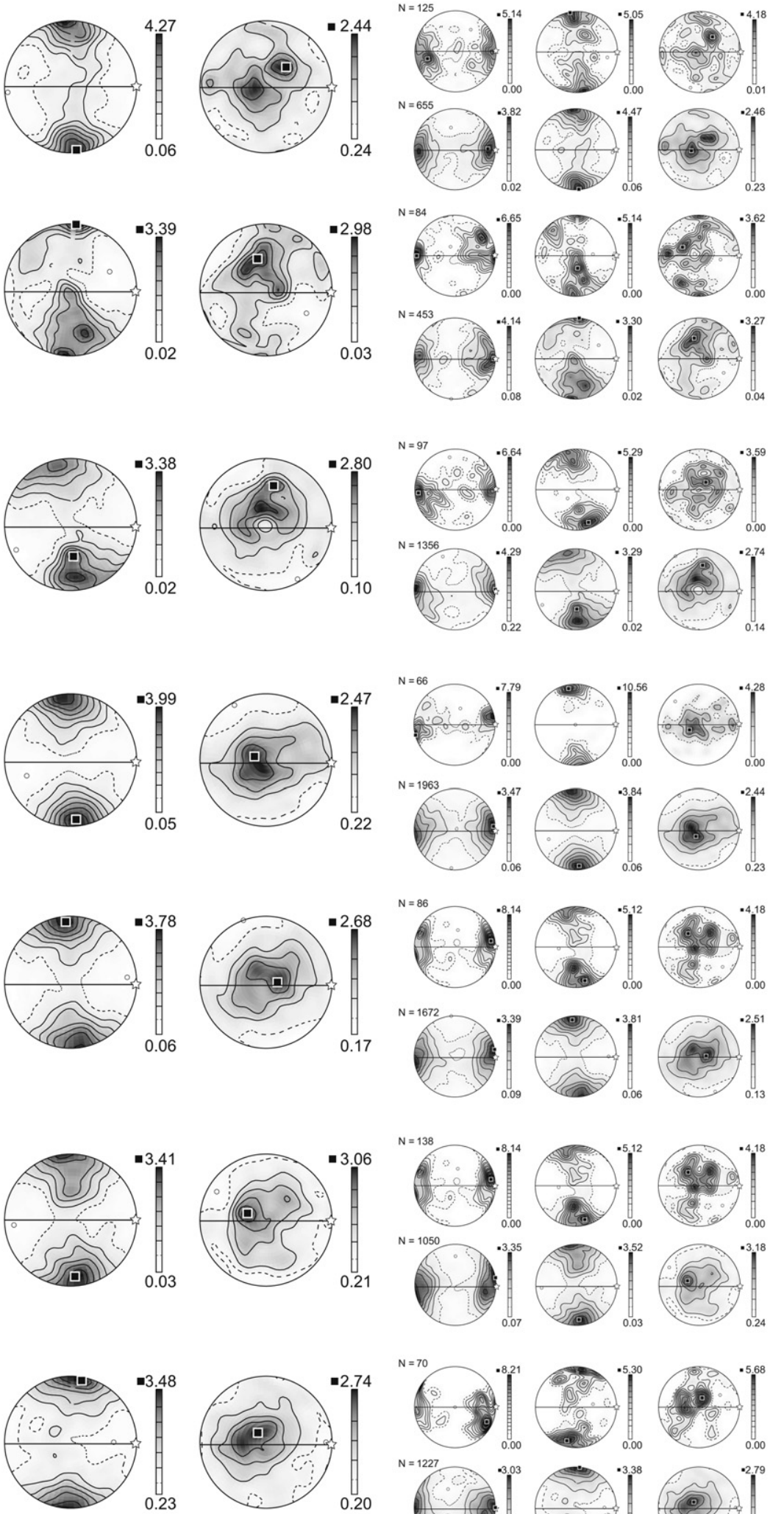
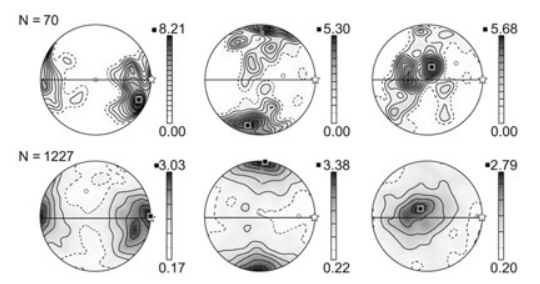
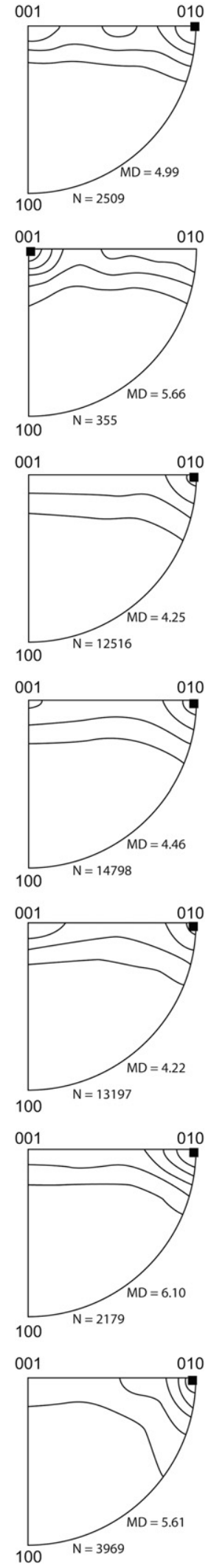

Fig. 3. (continued). 
[100]

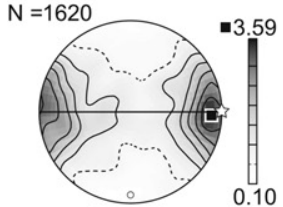

$n v 161-J=2.80$
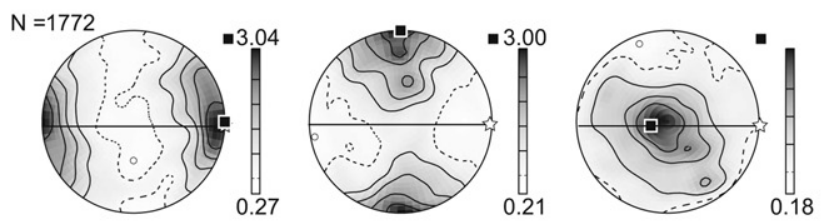

$n v 168-J=2.67$
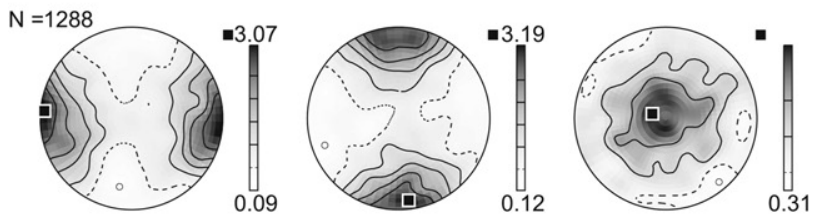

$n v 162-J=2.58$
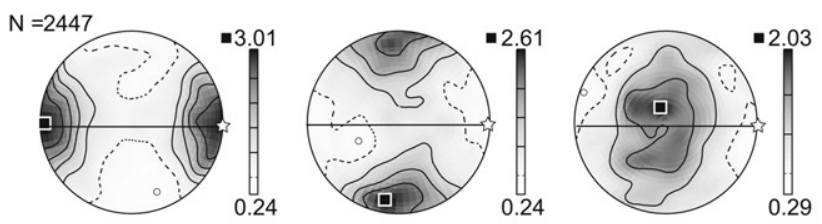

$n v 165-J=2.43$
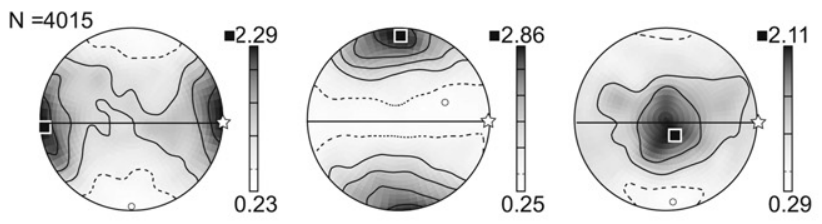

$\lg 101-J=2.01$
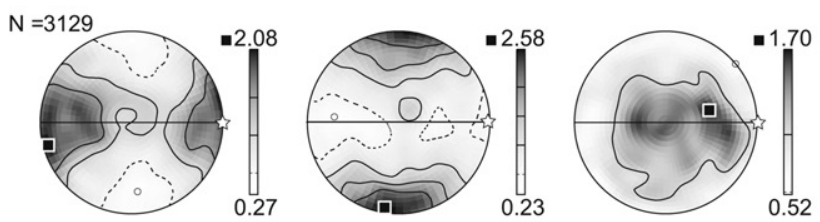

nv129 $-J=1.86$

[001]

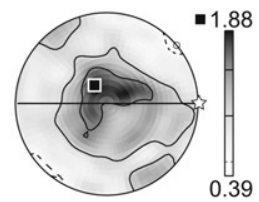

\section{.39}

(1)
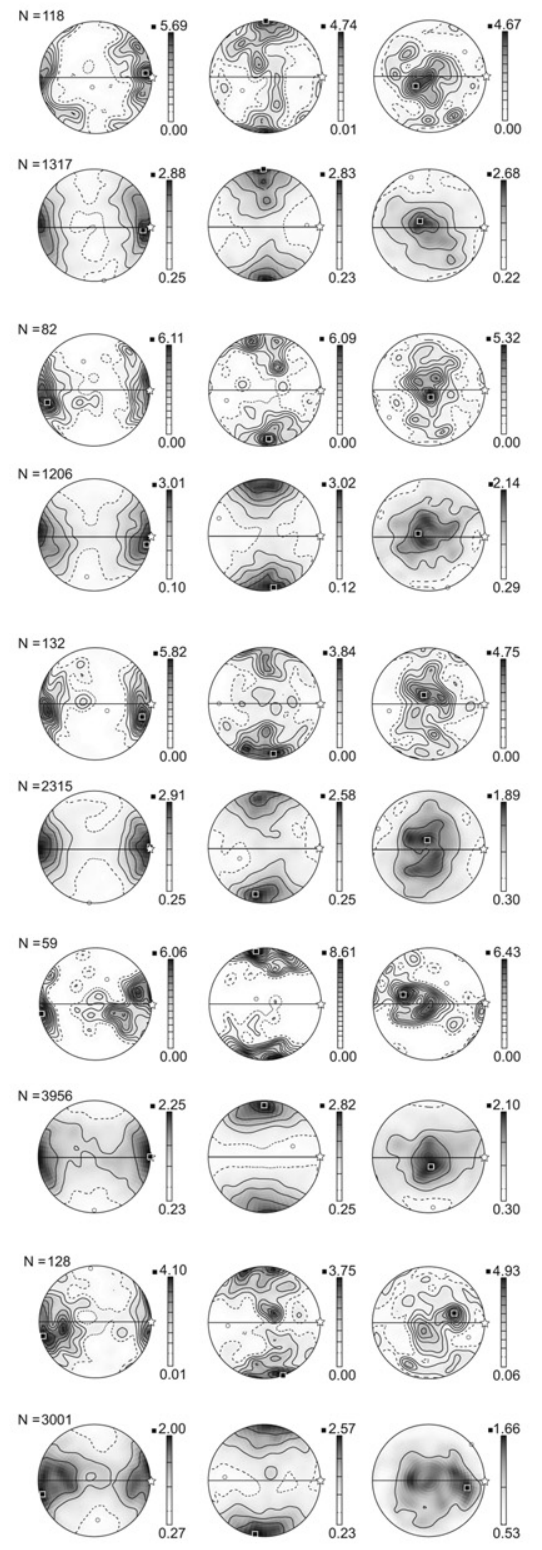

Fig. 3. (continued).

axes (Fig. 8). This suggests that deviatoric stresses and strain rates, which are the primary factor controlling recrystallized grain size (Austin and Evans, 2007), do not influence the dispersion of [100] axes. This observation is in contradiction with experimental results, which showed that at similar finite strains olivine aggregates deformed at higher stresses displayed weaker CPO (Zhang et al., 2000). This disagreement is most likely due to the predominance of subgrain rotation as the main nucleation mechanism in our samples, as in most naturally deformed peridotites, over bulging (grain boundary migration) that was observed to be an important nucleation mechanism in the experiments (Zhang et al., 2000). Independence of the dispersion of [100] axes from recrystallized grain size also suggests that grain growth is not orientation sensitive. This may imply that, at low stress and relatively high temperature conditions, beside dynamic factors, like variations in dislocation 

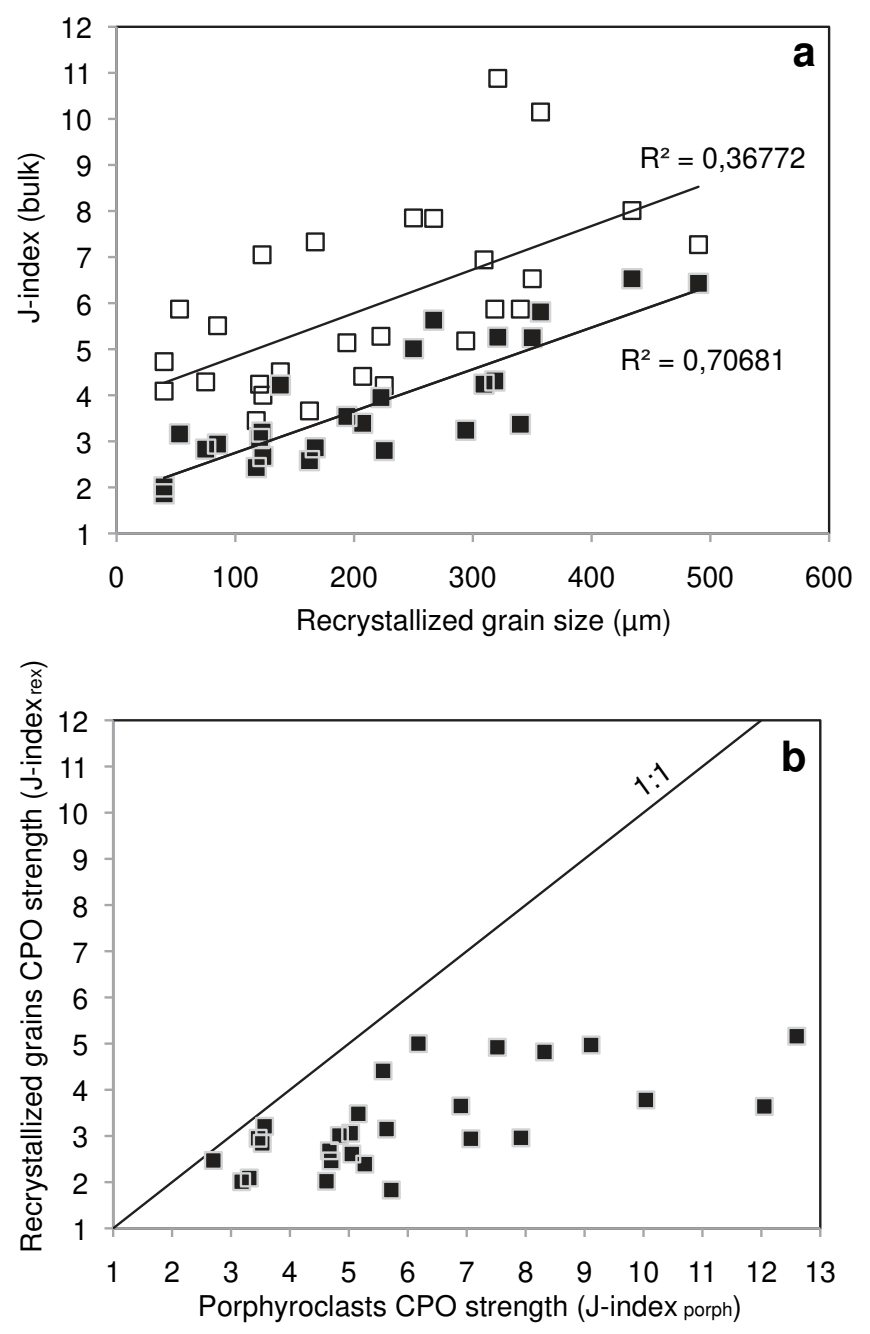

Fig. 4. (a) Strength of olivine CPO ( $J$-index) vs. recrystallized grain size in the studied xenoliths. (b) Comparison between the strengths of the olivine CPO of the porphyroclasts and the recrystallized fractions in the studied xenoliths. Full squares indicate $J$-indexes calculated using 1 measurement point per grain; empty squares indicate $J$-indexes calculated using 1 measurement point per pixel of the orientation map.

density between neighboring grains, grain boundary area reduction may also be an important driving force for grain growth.

Although the dispersion of [100] axes does not depend on the recrystallized grain size there is an obvious positive correlation between the CPO strength, characterized by the $J$-index, and the recrystallized grain size (Fig. 4). A similar variation in CPO strength with recrystallized grain size has also been shown for mantle rocks from shear zones in the Oman ophiolite (Michibayashi et al., 2006) and in the Lanzo massif in the Alps (Kaczmarek and Tommasi, 2011), where the coarse-grained domains on the edge of the shear zone show much stronger olivine CPO than the mylonites from the central part of the shear zone.

Which factors do control the fabric strength in a rock deforming by an association of dislocation glide and dynamic recrystallization? One important aspect, discussed earlier, is the crystallographic control of porphyroclasts (parent grains) on the orientation of the nucleating grains. This implies that the CPO strength of recrystallized grains (formed by subgrain rotation recrystallization) in a rock with originally strong $\mathrm{CPO}$ is expected

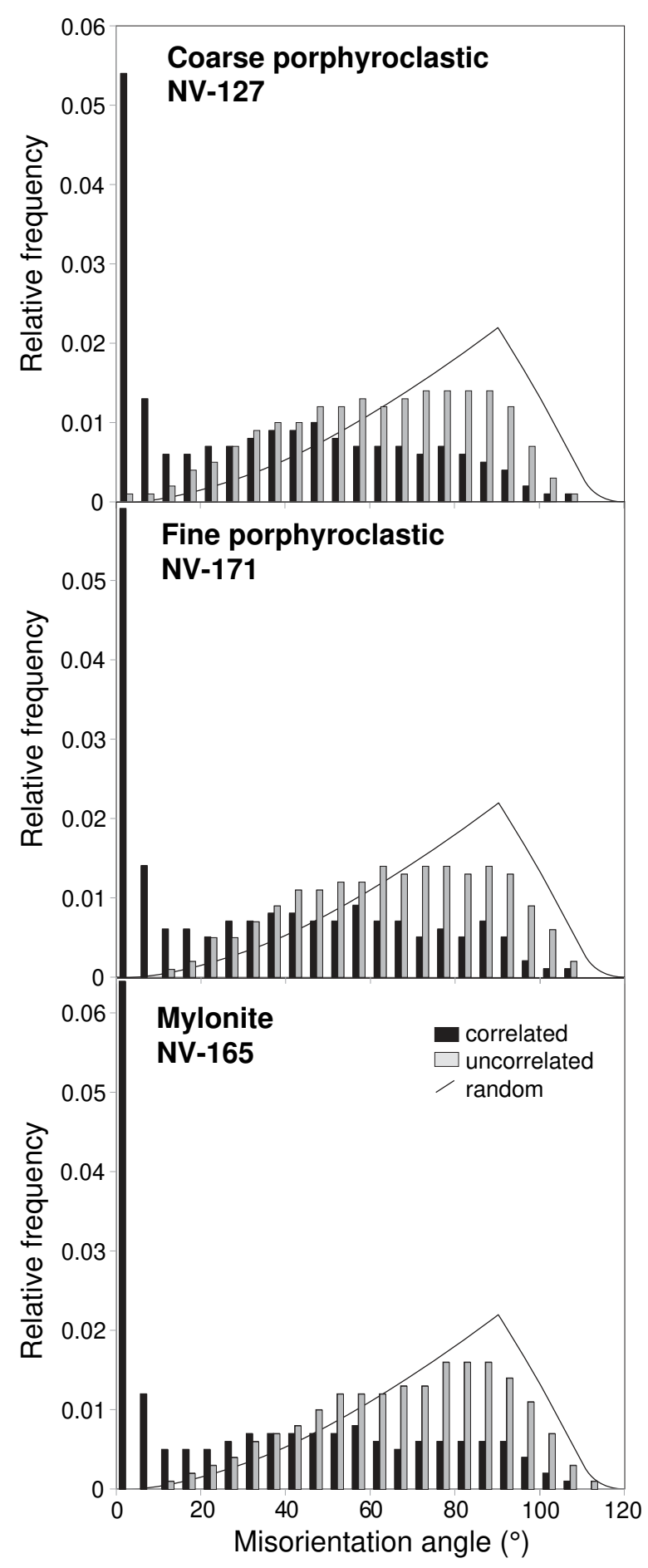

Fig. 5. Misorientation angles distributions for typical coarse porphyroclastic, finegrained porphyroclastic, and mylonitic xenoliths. Note the predominance of lowangle (subgrain) boundaries (misorientations $<10^{\circ}$ ) in all cases. Correlated misorientations (black) are those measured between neighboring points, uncorrelated misorientations (light gray) are measured between randomly selected points, and random indicates the theoretical distribution for a random crystallographic orientation.

to be higher than that of a rock displaying an originally weaker CPO. Another important factor is the recrystallized rock volume, which shows a negative correlation with the CPO strength (Fig. 9). Finite strain is suggested to be the most important 

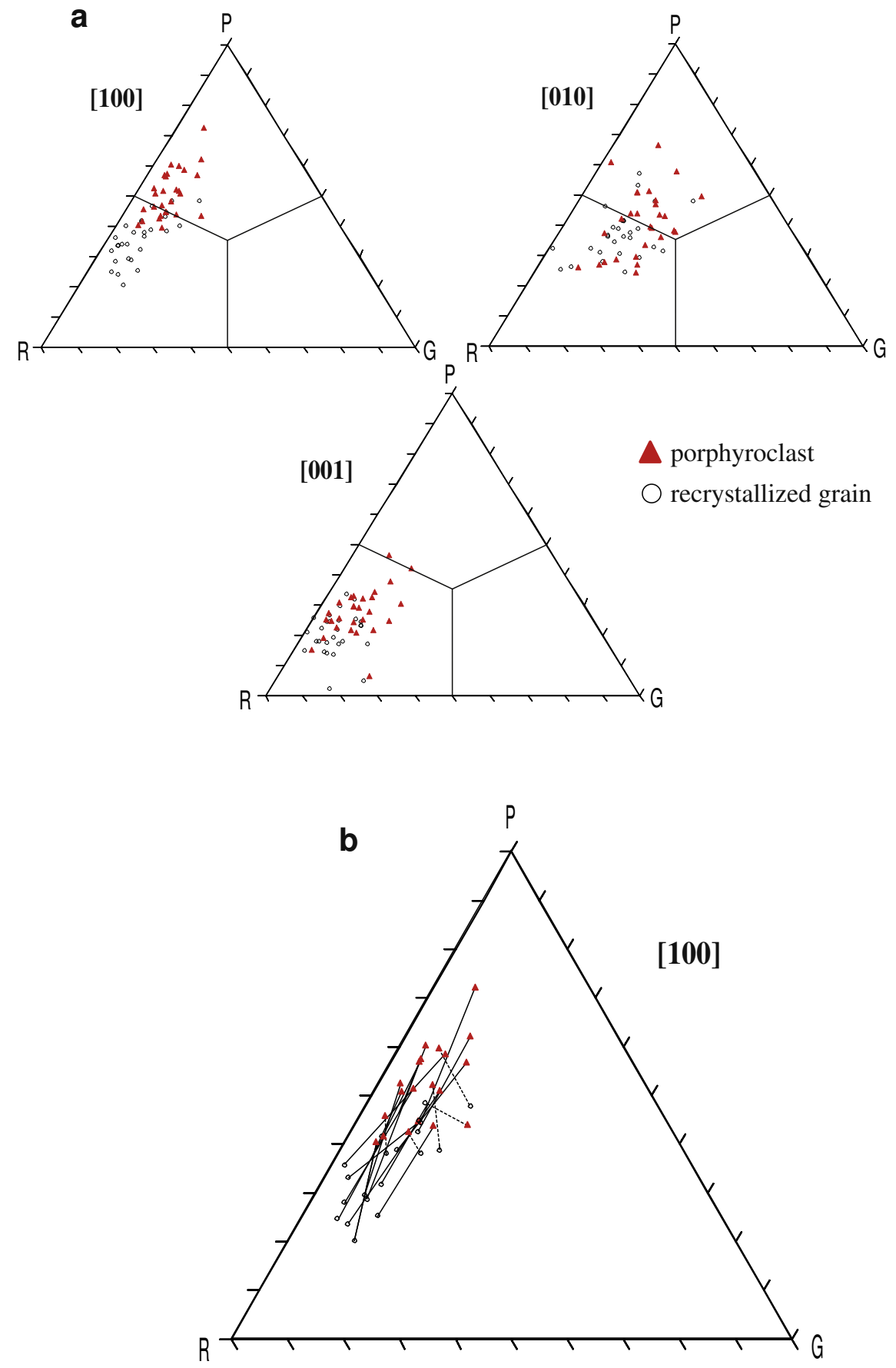

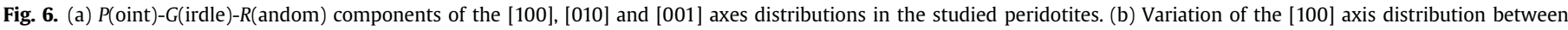

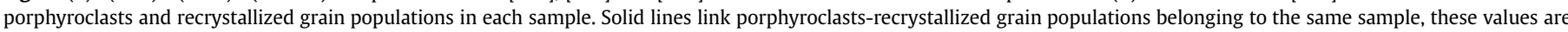

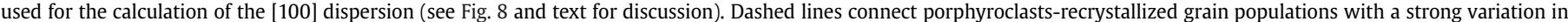

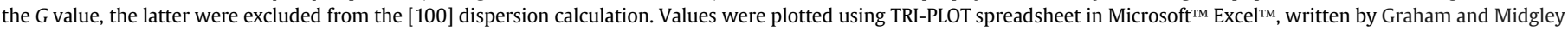
(2000).

factor determining the volume of recrystallized grains at intermediate temperature and stress conditions prevailing in the upper levels of the lithospheric mantle, which are the conditions sampled in both the present study and Michibayashi et al. (2006). However, under high-temperature, low-stress conditions as those that prevail at the base of the lithosphere and in the asthenosphere, fast growth rates of the deformation-free recrystallized grains, which slow as these "new" grains start to deform, probably result in a continuous grain size distribution and in maintenance of low "recrystallized" volume fractions, which will lead in turn to stronger steady-state CPO. We suggest therefore that the impact of strain rate, stress, and temperature on the CPO strength is directly linked to their effect on the recrystallized volume fraction. 


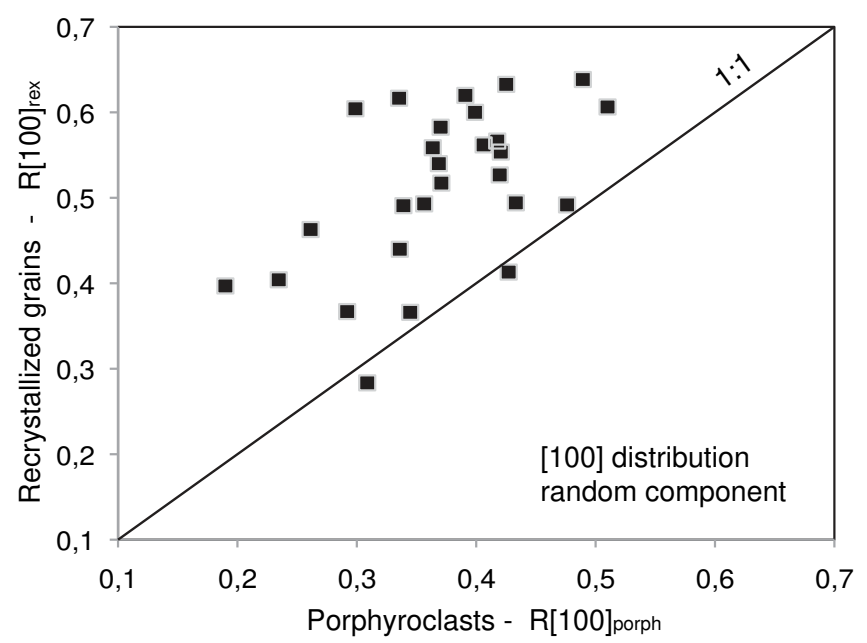

Fig. 7. $R_{\mathrm{r}}$ vs. $R_{\mathrm{p}}$ for $[100]$ in the studied xenoliths. See text for definition of the parameters.
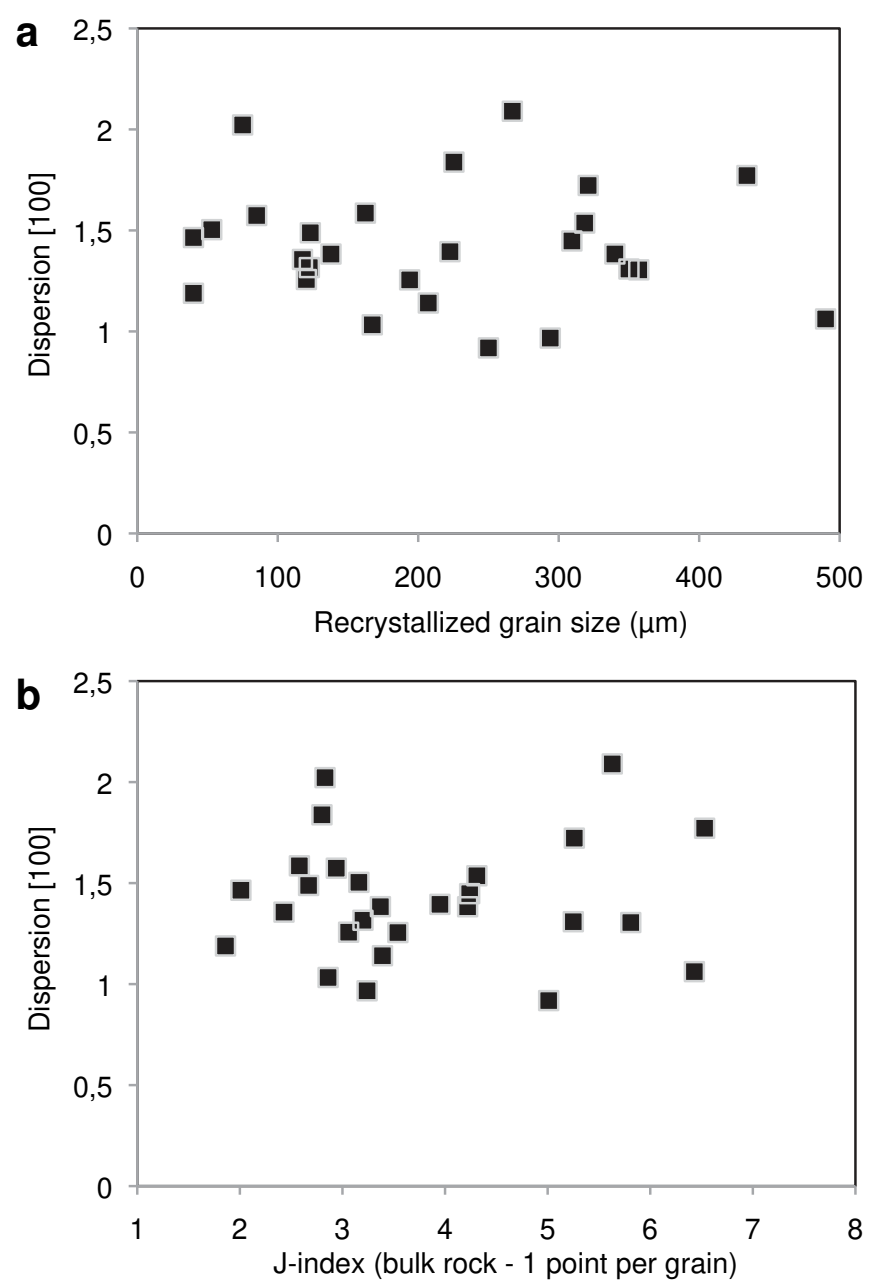

Fig. 8. [100] dispersion (see definition in text) vs. (a) Recrystallized grain size and (b) Jindex of olivine in the studied xenoliths. Note the absence or weak dependence of the dispersion of [100] on both parameters.

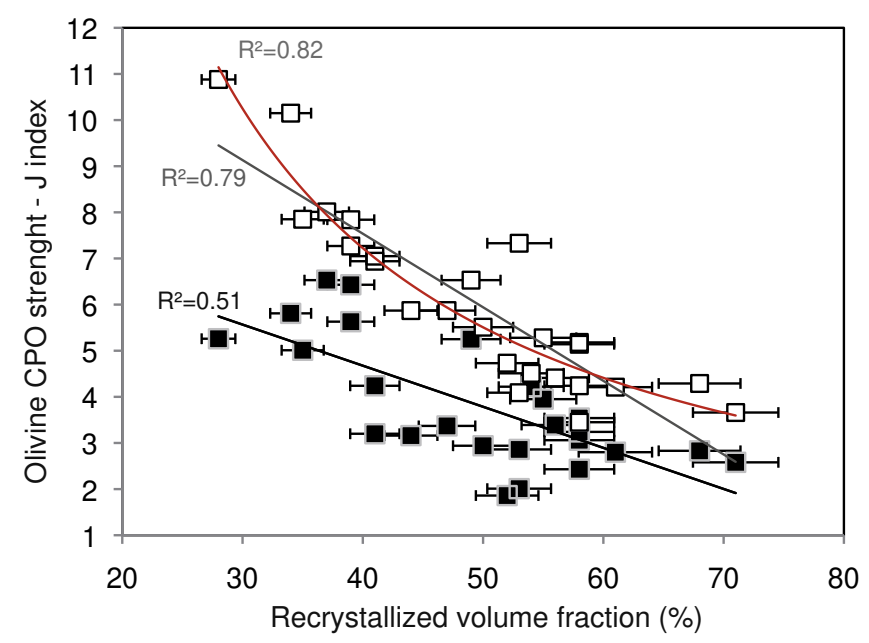

Fig. 9. Olivine $J$-index vs. recrystallized volume in the studied xenoliths. Full squares indicate $J$-indexes calculated using 1 measurement point per grain; empty squares indicate $J$-indexes calculated using 1 measurement point per pixel of the orientation map. Note the remarkable negative correlation between the two parameters.

\section{Conclusions}

Detailed analysis of the deformation microstructures and crystal preferred orientations of a series of mantle xenoliths derived from a $20 \mathrm{~km}$-deep section in the shallow subcontinental lithosphere and recording deformation under varied temperature, stress and strain rate conditions allowed quantifying the effects of intracrystalline deformation and recrystallization on the strength of olivine crystal preferred orientations and hence on the anisotropy of physical properties in the upper mantle.

There is a strong crystallographic control by the deformation $\mathrm{CPO}$, characterized by the porphyroclasts orientations, on the crystallographic orientation of the recrystallized grains, suggesting that subgrain rotation is the dominant nucleation mechanism over a large range of strain rates, deviatoric stresses, and temperatures. This implies that strain-induced olivine CPO may be weakened, but not erased by dynamic recrystallization. Subgrain rotation recrystallization results in a stronger dispersion of olivine [100] than of [010] or [001], because dominant activation of [100]\{0kl\} slip systems leads to formation of a large number of (100) tilt boundaries.

Although deviatoric stress and strain rate conditions control recrystallized grain sizes, they have no effect on the dispersion of olivine [100] axes with respect to the parent grains orientation. A positive correlation between recrystallized grain sizes and the strength of olivine CPO is nevertheless observed. The higher dispersion of the olivine CPO in the mylonites may be attributed to a more important contribution of bulging processes to nucleation, which allows for higher misorientations between parent and recrystallized grains. Stronger olivine CPO in the coarse porphyroclastic peridotites may also be favored by more effective grain boundary migration allowing for selective growth of crystals in easy glide orientations in those samples deformed at higher temperatures. Finally, although the studied samples present no clear evidence for grain boundary sliding, this process might also contribute to a higher dispersion of the $\mathrm{CPO}$ in the finest-grained samples.

As the anisotropy of physical properties depend on the relative volume of the different crystal orientations, the most important factor controlling the strength of olivine CPO and hence the anisotropy in the shallow lithospheric mantle is the recrystallized volume, which depends primarily on the finite strain. However, strain rate and temperature conditions also play a role via the 
interplay between deformation, nucleation, and growth rates. Deformation under low temperature, high-stress conditions that prevail in the shallow lithospheric mantle should result therefore in weaker olivine CPO and hence in lower anisotropy than deformation under deep lithospheric or asthenospheric conditions.

\section{Acknowledgements}

We thank the Lithosphere Fluid Research Laboratory in Budapest for giving access to their mantle xenoliths collection and for sample preparation. D. Mainprice provided the softwares used for analyzing and plotting CPO data. We thank C. Nevado and D. Delmas for the high quality polished thin sections for EBSD measurements. GF postdoctoral position in Montpellier was funded by the French Ministère de l'Enseignement Supérieur et de la Recherche. This study was funded by the Institut National des Sciences de l'Univers (CNRS/INSU) program 'Structure, Evolution et Dynamique de l'Intérieur de la Terre', the Hungarian-French bilateral cooperation program PAI BALATON, the Bolyai Scholarship Fund, and the National Science Foundation (OTKA F 67917).

\section{References}

Amelinckx, S., Dekeyser, W., 1959. The structure and properties of grain boundaries. Solid State Physics 8, 325-499.

Austin, N.J., Evans, B., 2007. Paleowattmeters: a scaling relation for dynamically recrystallized grain size. Geology 35 (4), 343-346.

Avé Lallemant, H.G., Carter, N.L., 1970. Syntectonic recrystallization of olivine and modes of flow in the upper mantle. Bulletin of the Geological Society of America 81, 2203-2220.

Bunge, H.J., 1982. Texture Analysis in Materials Science. Butterworths, London.

Ben Ismail, W., Mainprice, D., 1998. An olivine fabric database: an overview of upper mantle fabrics and seismic anisotropy. Tectonophysics 296, 145-157.

Bystricky, M., Kunze, K., Burlini, L., Burg, J.-P., 2000. High shear strain of olivine aggregates: rheological and seismic consequences. Science 290, 1564-1567.

Carter, N.L., 1976. Steady state flow of rocks of rocks. Review in Geophysics and Space Physics 14, 301-353.

Csontos, L., 1995. Tertiary tectonic evolution of the Intra-Carpathian area: a review. Acta Vulcanology 7, 1-13.

Darot, M., Gueguen, Y., 1981. High-temperature creep of forsterite single crystals. Journal of Geophysical Research 86, 6219-6234.

Falus, G., Tommasi, A., Ingrin, J., Szabó, Cs, 2008. Deformation and seismic anisotropy of the lithospheric mantle in the southeastern Carpathians inferred from the study of mantle xenoliths. Earth and Planetary Science Letters 272, 50-64.

Fliervoet, T.F., White, S.H., 1995. Quartz deformation in a very fine grained quartzofeldspathic mylonite: a lack of evidence for dominant grain boundary sliding deformation. Journal of Structural Geology 17, 1095-1110.

Gatzemeier, A., Tommasi, A., 2006. Flow and electrical anisotropy in the upper mantle: finite-element models constraints on the effects of olivine crystal preferred orientation and microstructure. Physics of the Earth Planetary Interiors $158,92-106$

Graham, D.J., Midgley, N.G., 2000. Graphical representation of particle shape using triangular diagrams: an Excel spreadsheet method. Earth Surface Processes and Landforms 25, 1473-1477.

Heidelbach, F., Stretton, I., Langenhorst, F., Mackwell, S., 2003. Fabric evolution during high shear strain deformation of magnesiowüstite (Mg0.8Fe0.2O). Journal of Geophysical Research 108, 2154. doi:10.1029/2001JB001632.

Humbert, M., Cey, N., Mullier, J., Esling, C., 1996. Determination of mean orientation from a cloud of orientations. Application to electron backscatterring pattern measurements. Journal of Applied Crystallography 29, 662-666.

Ivan, M., Popa, M., Ghica, D., 2008. SKS splitting observed at Romanian broad-band seismic networ. Tectonophysics 462, 89-98.
Kaczmarek, M.-A., Tommasi, A., 2011. Anatomy of an extensional shear zone in the mantle (Lanzo massif, Italy). Geochemistry Geophysics Geosystems. doi:10.1029/2011GC003627.

Karato, S.I., Toriumi, M., Fujii, T., 1980. Dynamic recrystallization of olivine single crystals during high-temperature creep. Geophysical Research Letters 7, 649-652.

Karato, S.I., 1988. The role of recrystallization in the preferred orientation of olivine. Physics of Earth and Planetary Interiors 51, 107-122.

Kobayashi, Y., 1974. Anisotropy of thermal diffusivity in olivine, pyroxene, and dunite. Journal of Physics of the Earth 22, 359-373.

Lloyd, G.E., Farmer, A.B., Mainprice, D., 1997. Misorientation analysis and orientation of subgrain and grain boundaries. Tectonophysics 279, 55-78.

Mainprice, D., Barruol, G., Ben Ismail, W., 2000. The seismic anisotropy of the Earth's mantle: from single crystal to polycrystal. In: Karato, S.I. (Ed.), Earth's Deep Interior: Mineral Physics and Tomography from the Atomic to the Global Scale. AGU, Washington, DC, pp. 237-264.

Michibayashi, K., Ina, T., Kanagawa, K., 2006. The effect of dynamic recrystallization on olivine fabric and seismic anisotropy: insights from a ductile shear zone in the Oman ophiolite. Earth and Planetary Science Letters 244, 695-708.

Nicolas, A., Boudier, F., Boullier, A.M., 1973. Mechanism of flow in naturally and experimentally deformed peridotites. American Journal of Science 273, 853-876.

Nicolas, A., Christensen, N.I., 1987. Formation of anisotropy in upper mantle peridotites - a review. In: Fuchs, K., Froidevaux, C. (Eds.), Composition, Structure and Dynamics of the Lithosphere-Asthenosphere System. AGU Geodynamics Series, vol. 16. American Geophysical Union, Washington, DC, pp. 111-123.

Panaiotu, C.G., Pécskay, Z., Hambach, U., Seghedi, I., Panaiotu, C.E., Itaya, T., Orleanu, M., Szakács, A., 2004. Short-lived quaternary volcanism in the Persan Mountains (Romania) revealed by combined $\mathrm{K}-\mathrm{Ar}$ and paleomagnetic data. Geologica Carpathica 55, 333-339.

Poirier, J.-P., Nicolas, A., 1975. Deformation induced recrystallization due to progressive misorientation of subgrains, with special reference to mantle peridotites. Journal of Geology 83, 707-720.

Soustelle, V., Tommasi, A., Demouchy, S., Ionov, D., 2010. Deformation and fluid-rock interactions in the supra-subduction mantle: microstructures and water contents in peridotite xenoliths from the Avacha Volcano, Kamchatka. Journal of Petrology 51, 363-394.

Takeshita, T., Wenk, H.-R., Canova, G.R., Molinari, A., 1990. Simulation of dislocationassisted plastic deformation in olivine polycrystals. In: Barber, J., Meredith, P.G. (Eds.), Deformation Processes in Minerals, Ceramics and Rocks. Unwin Hyman, London, pp. 365-376.

Tommasi, A., Tikoff, B., Vauchez, A., 1999. Upper mantle tectonics: threedimensional deformation, olivine crystallographic fabrics and seismic properties. Earth and Planetary Science Letters 168, 173-186.

Tommasi, A., Mainprice, D., Canova, G., Chastel, Y., 2000. Viscoplastic self-consistent and equilibrium-based modelling of olivine lattice preferred orientations. Implications for upper mantle seismic anisotropy. Journal of Geophysical Research 105, 7893-7908.

Tommasi, A., Gibert, B., Seipold, U., Mainprice, D., 2001. Anisotropy of thermal diffusivity in the upper mantle. Nature 411, 783-786.

Tommasi, A., Vauchez, A., 2001. Continental rifting parallel to ancient collisional belts: an effect of the mechanical anisotropy of the lithospheric mantle. Earth and Planetary Science Letters 185, 199-210.

Tommasi, A., Knoll, M., Vauchez, A., Signorelli, J., Thoraval, C., Logé, R., 2009. Structural reactivation in plate tectonics controlled by olivine crystal anisotropy. Nature Geoscience 2, 423-427. doi:10.1038/NGEO528.

Van der Wal, D., Chopra, P., Drury, M., Fitzgerald, J., 1993. Relationships between dynamically recrystallized grain size and deformation conditions in experimentally deformed olivine rocks. Geophysical Research Letters 20, 1479-1482.

Vollmer, F.W., 1990. An application of eigenvalue methods to structural strain domain analysis. Bulletin Geological Society of America 102, 786-791.

Wenk, H.R., Bennet, K., Canova, G., Molinari, A., 1989. Modelling plastic deformation of peridotite with the self-consistent theory. Journal of Geophysical Research 96, 8337-8349.

Woodcock, N.H., Naylor, M.A., 1983. Randomness testing in three dimensional orientation data. Journal of Structural Geology 5, 539-548.

Zhang, S., Karato, S., 1995. Lattice preferred orientation of olivine aggregates deformed in simple shear. Nature 375, 774-777.

Zhang, S., Karato, S.I., FitzGerald, J.D., Faul, U.H., Zhou, Y., 2000. Simple shear deformation of olivine aggregates. Tectonophysics 316, 133-152. 